\title{
Retention of Fuel Borne Catalyst Particles by Diesel Particle Filter Systems
}

\author{
131
}

A. Mayer, A. Ulrich, J. Czerwinski, U. Matter and M. Wyser

TTM, EMPA, AFHB, ETHZ, BUWAL

Reprinted From: Diesel Emission Measurement and Modeling

(SP-1755 / SP-1754CD) 
All rights reserved. No part of this publication may be reproduced, stored in a retrieval system, or transmitted, in any form or by any means, electronic, mechanical, photocopying, recording, or otherwise, without the prior written permission of SAE.

For permission and licensing requests contact:

SAE Permissions

400 Commonwealth Drive

Warrendale, PA 15096-0001-USA

Email: permissions@sae.org

Fax: $\quad 724-772-4028$

Tel: $\quad 724-772-4891$

\section{우를}

Global Mobility Database ${ }^{\circledR}$

All SAE papers, standards, and selected

books are abstracted and indexed in the

Global Mobility Database.

For multiple print copies contact:

SAE Customer Service

Tel: $\quad 877-606-7323$ (inside USA and Canada)

Tel: $\quad$ 724-776-4970 (outside USA)

Fax: $\quad$ 724-776-1615

Email: CustomerService@sae.org

\section{ISSN 0148-7191}

\section{Copyright $\odot 2003$ SAE International}

Positions and opinions advanced in this paper are those of the author(s) and not necessarily those of SAE. The author is solely responsible for the content of the paper. A process is available by which discussions will be printed with the paper if it is published in SAE Transactions.

Persons wishing to submit papers to be considered for presentation or publication by SAE should send the manuscript or a 300 word abstract of a proposed manuscript to: Secretary, Engineering Meetings Board, SAE.

\section{Printed in USA}




\title{
Retention of Fuel Borne Catalyst Particles by Diesel Particle Filter Systems
}

\author{
A. Mayer, A. Ulrich, J. Czerwinski, U. Matter and M. Wyser \\ TTM, EMPA, AFHB, ETHZ, BUWAL
}

Copyright $(\odot) 2003$ SAE international

\begin{abstract}
Metallic substances, usually added to fuel as organic compounds are, as fuel additives proven to curtail particulate emissions from diesel engines and, as fuel borne catalysts (FBC), to promote regeneration of particle traps. During combustion, these substances form catalytic metal oxides and exit the combustion chamber as ultra-fine solid clusters in the mobility diameter range of $5-30 \mathrm{~nm}$.
\end{abstract}

Particles of this size and composition have a health impact and should not enter the respiratory air. FBC should therefore only be used together with particle traps, which can efficiently collect these metal oxide particles at all operating conditions. This and other requirements are stipulated in the VERT suitability tests for particle trap systems. The approval procedure includes a particle size-specific analysis to verify trap penetration in trace quantities. The results of these suitability tests are reported together with methods, for sample extraction and analysis, to detect trace quantities of metallic particulate matter in fine resolution impactors.

Results of an offroad utility vehicle engine in ISO 8178 cycle are shown as an example. The results confirm that modern particle filters can trap these ultrafine particles with an efficiency $>99 \%$.

Further research is needed to investigate whether operation conditions may exist, particularly during regeneration of fully loaded traps at high space velocity conditions, where noticeably higher emissions occur.

The results substantiate the necessity to very carefully test particle trap systems with FBC regeneration, and verify their secondary emissions.

\section{RESEARCH MOTIVATION}

Catalyst fuel additives are a recognized effective method to curtail soot formation during the engine combustion, and to promote trap regeneration [1].
The catalytic effects of these additives substantially lower the soot ignition temperature by diminishing the activation energy [2]. The soot light-off is significantly accelerated and simultaneously the formation of polycyclic aromatics inhibited [3, 4].

The additive substances are mixed with the fuel mainly as metal organic compounds in concentrations of 5-20 $\mathrm{mg}$ metal per $\mathrm{kg}$ fuel. They are carefully formulated to mix perfectly and are stable with the diesel fuel. The additives are well distributed within each fuel microdroplet in the combustion process. The catalytic effective metal oxides are only formed during the combustion.

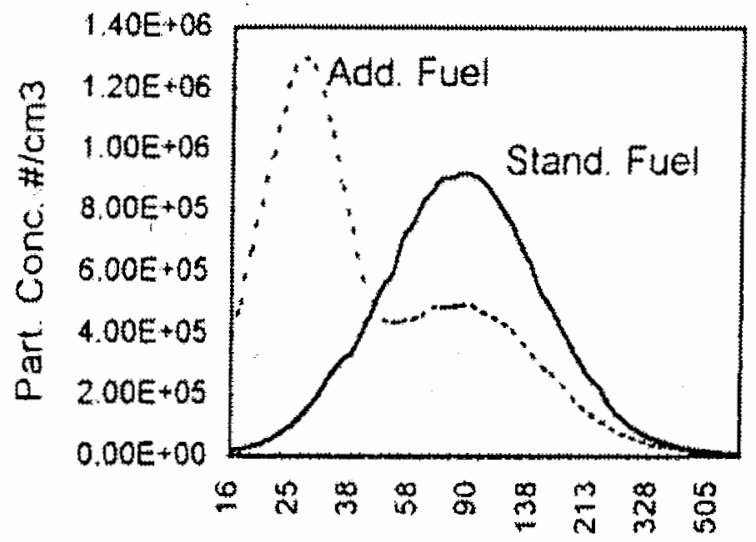

Size $(\mathrm{nm})$

Fig. 1: Particle size distribution in the exhaust of a Diesel engine with and without fuel additive [5]

These metal oxides form tiny clusters of solid particles in the range $5-30 \mathrm{~nm}$. These are embedded in the soot particles. That is desirable. Alternatively, particularly at high dosage rates, these could also be emitted independently of the soot particles. 
The exhaust gases from diesel engines, using such FBC doted fuels, often have bimodal particle distributions (Fig.1). This phenomenon, releasing metal oxide particles in the sub-micron range, is suspected to be injurious because of the heavy metal particles. Hence, it is addressed in the Swiss Ordinance on Air Pollution Control OAPC [6]. The phenomenon has also been meticulously investigated by $[7,8]$ the VERT project for implementing particle trap technology in offroad deployment in Switzerland.

The FBC in particle trap technology have mainly been Iron, Copper, Strontium, Cerium and Platinum. The toxicity of these metals in the form emitted by Diesel engines is the subject of many investigations not yet concluded $[9,10]$. Moreover, the pertinent metal oxide particles, similar to all insoluble particles in the submicron range, must be regarded as possibly highly injurious [11].

The deployment of FBC without efficient filtration of these particles must therefore be discouraged. On the other hand together with particle traps, the use of FBC is very advisable, because these promote the regeneration particularly in critical highly emitting engines deployed under varying load. Moreover, FBC are suitable to lower the energy requirements for active regeneration methods. FBC are thus gaining relevance both for equipping new engines and retrofitting existing engines [12].

The prerequisite for approving such trap systems with additive regeneration is adequate testing. Under no circumstances shall toxic quantities of these heavy metal substances be emitted into respiratory air. That is the topic of this paper.

\section{SWISS STIPULATIONS}

FBC used with particle traps must comply with the directives of the Swiss environmental authority [13]. The stipulations are experimental verification of emissions during representative suitability tests:

- VSET/1: (VERT secondary emissions test): Proof that the fuel additives do not form any additional gaseous toxic substances [14]. The test procedure comprises analysis of about 200 substances, e.g. $\mathrm{PAH}$, Nitro-PAH, Dioxins, Furanes, etc.[15].

- VSET/2: Size-specific metal analysis of cleaned gas after the trap to determine the trap penetration of additive particles. The evaluation is substance specific. Metals that normally occur in exhaust gas (Iron, Copper) must have lower emission levels than the baseline.

- VFT (VERT filter test): For each trap/additive combination, proof is required that the filtration rate for additive particles in the size range 20-200 $\mathrm{nm}$ is comparable with rates for soot particles. A bimodal distribution in the cleaned gas, indicating an increased concentration of additive particles in certain size classes, is not permissible.
Moreover, all new additive substances must be registered and their toxicity classified. An automatic dosage of the additive is mandatory for trap deployment in road traffic. The dosage arrangement must also have a electronic safety mechanism that automatically stops additive dosage on detection of any trap failure. Using additives without particle traps is generally prohibited in Switzerland.

\section{VSET TEST METHODOLOGY}

The purpose of the VSET test is to identify traces of toxic emissions. Hence, the test cycle must fulfill these conditions:

- The test cycle must be representative of typical operational deployment.

- The test cycle must contain worst case conditions for the formation of secondary toxic emissions.

- The cycle must be long enough to collect an adequate sample for trace analysis.

- The sampling procedure must be optimized for the analyte to be determined (filter material, sampling equipment, etc.).

This test procedure was introduced during the implementation of trap technology for offroad machines. The pertinent certification cycle ISO 8178 C1 was adopted.

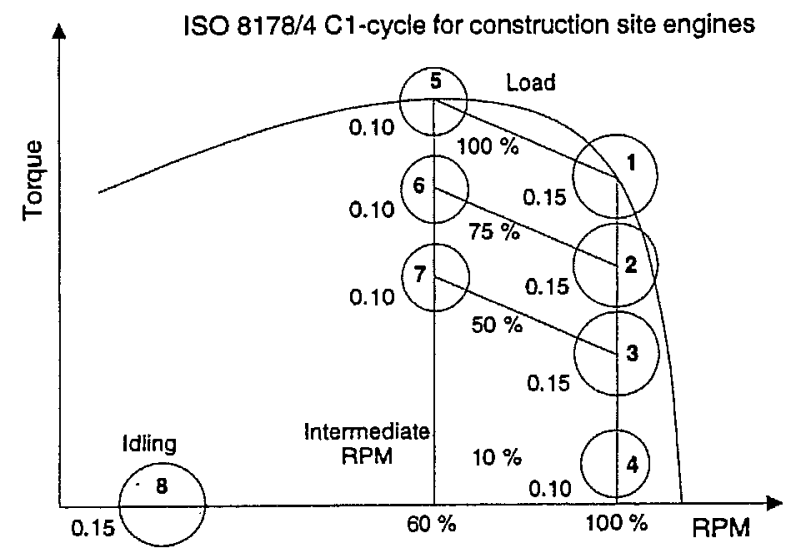

Fig. 2: Test cycle for VSET as per ISO 8178/4 C1

The cycle is normally driven in the sequence shown. The holding times in minutes per operating point correspond to the weighting factor. The entire duration of the cycle is thus 100 minutes, which includes the transition from one operating point to the next. The cycle is driven two to four times in sequence to provide a sufficient sampling period. Thus the sampling is throughout a total cycle time of 200 to 400 minutes. This cycle is an industry-wide consensus considered representative for the operation of construction site machines. All characteristic conditions for the formation and emission of toxic substances are simulated during the test. Consequently, these pollutants are a realistic proportion of the integral result. 
Fig.3 is an example of the exhaust gas temperature distribution before and after the trap.

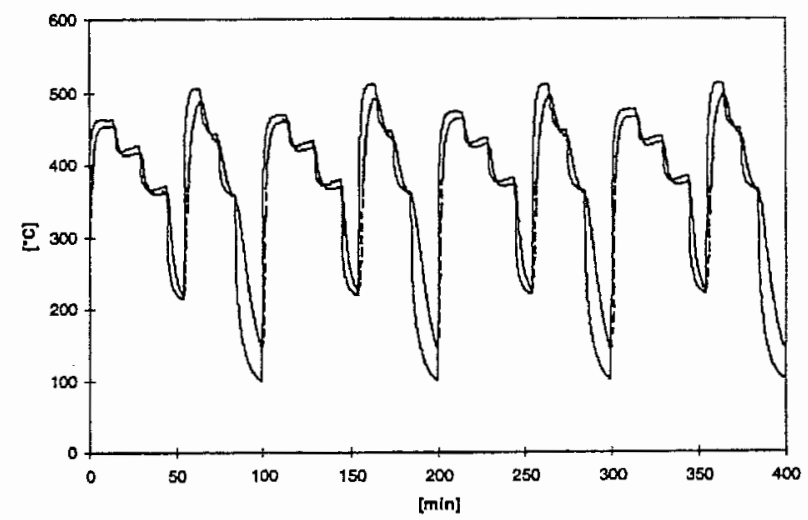

Fig. 3: Temperature profiles before/after trap during four ISO 8178/4 C1 cycles

The described test cycle traverses the entire temperature range from idling temperature to full load and is held sufficiently long at each point. Besides the normal operating states, the cycle also contains the regeneration phase. During regeneration the deposited soot is converted under the catalytic influence of the FBC principally to $\mathrm{CO}_{2}$ along with some $\mathrm{CO}$ and $\mathrm{H}_{2} \mathrm{O}$.

Factually, this test sequence contains all important operating conditions of the trap; namely deposition, regeneration and continuous soot combustion at higher temperature, i.e. clean trap. This is decisive for the realistic evaluation of deposition and the penetration of additive particles.

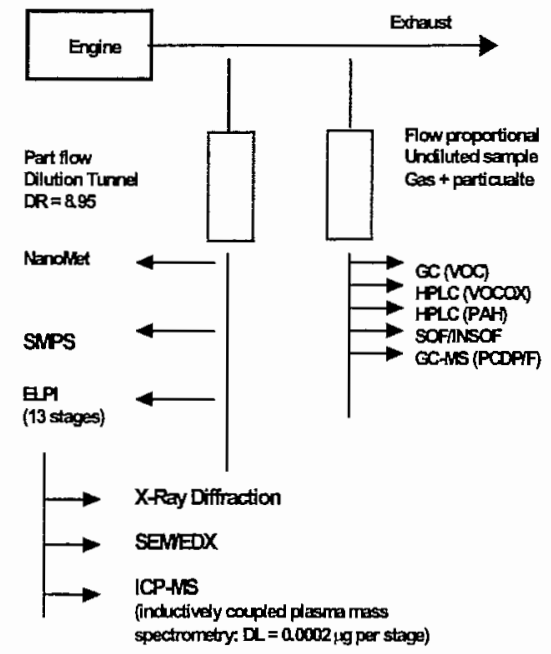

Fig. 4: Schematic arrangement of sample extraction during the secondary emissions tests.

Figure 4 shows the arrangement for sampling and measuring the raw emissions, i.e. without trap.

There are two sample extraction paths:

- From the undiluted exhaust gas, a flow proportional controlled sample is taken for the integral chemical analysis [15]. The undiluted extraction was chosen to obtain sufficient quantity of toxic substances within the given time. Even for toxic substances that are only expected in trace quantities, e.g. PCDD/F, this sample extraction method provides sufficient accuracy.

- From the dilution tunnel or, in the shown schematic, the partial dilution tunnel (AVL Smart Sampler), samples are taken for the particle analysis. A high dilution level is necessary to prevent condensate artifacts in this sample extraction method. Hence, it is essential that the subsequent measurement procedures have a very high sensitivity to correctly analyze the diluted samples.

The size classification of the particles using SMPS and NanoMet was described in a previous paper [16]). This paper focuses on the size-specific metal analysis. The aim of the investigation was to partition the aerosol into size classes. The collected particulate matter, in each size class, is examined chemically and also to characterize morphology and crystalline structure.

The size classification was done using the electrical low-pressure impactor ELPI, (Model Dekati). It partitions the sample into 12 particle size classes in the range of $20 \mathrm{~nm}$ to $1 \mu \mathrm{m}$ [17]. Figure 5 schematically illustrates the functioning of an impactor.

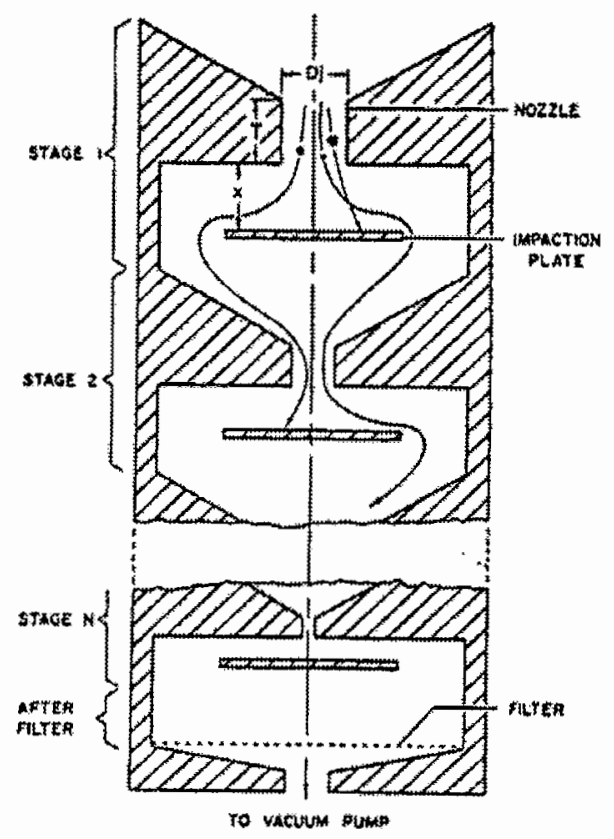

Fig. 5: Principle of an impactor for (aerodynamic) particle size classification of a sample

The particles are captured, according to size, on polycarbonate foils in the individual impactor stages. The impactor can process a volume flow of $10 \mathrm{l} / \mathrm{min}$. Thus only a partial (approx. 1:8000) portion of the exhaust gas quantity is available for sampling. Therefore, great care and high accuracy are necessary during the sampling, processing and analyses.

For the standard VSET test, the entire sampling is done once with and once without particle trap. The difference is interpreted as due to the particle trap. It is an acceptable assumption for back pressures up to 200 mbar, which do not modify the pertinent emission pattern of the engine. 


\section{METAL ANALYSIS METHODOLOGY}

The ultra-trace determination of metals requires a consequent optimization of the whole sampling procedure, sample preparation and analysis. Sampling mistakes can cause misleading results [18].

\section{Sample preparation and analysis}

All samples are digested with acid mixtures in a microwave oven. The vessels used for the digestion should be carefully cleaned before use to achieve best detection limits.

All cleaning digestions must be determined by inductively coupled plasma mass spectrometry ICPMS to check whether the contamination level is low enough. Only ultra-clean vessels should be used. Figure 6 shows an example of cleaning digestion levels and vessel choice for aerosol filter digestions.

Depending on the filter material and the analyte element, sampling filters are digested by the following acid mixtures in a microwave oven:

1. Nitric acid $\mathrm{HNO}_{3}$

2. A mixture of nitric acid $\mathrm{HNO}_{3}$ and hydrogen peroxide $\mathrm{H}_{2} \mathrm{O}_{2}$

3. A mixture of nitric acid, hydrochloric acid $\mathrm{HCl}$ and hydrogen peroxide $\mathrm{H}_{2} \mathrm{O}_{2}$

Only acids of ultra-pure quality (Merck) are used for digestion.

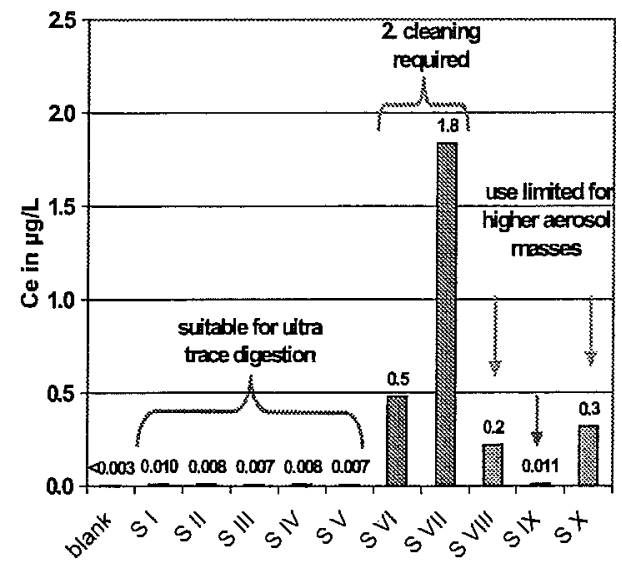

Fig. 6: Cerium determination for vessel selection after pre-cleaning digestion. Minimum 5 reagent blanks are processed similarly to determine the detection limits of the sample preparation procedure and the analysis method.

The resulting solutions are analyzed by inductively coupled plasma mass spectrometry (ICPMS). Depending on the analyte, a quadruple ICPMS (ELAN 6000 , Perkin Elmer/Sciex) or a high resolution ICPMS (ELEMENT 2, Thermofinnigan) is used.

Reliable results can only be achieved if the detection limit of the entire procedure, including sampling, sample preparation and analysis are determined. Therefore, blanks of fresh filter material and field- blanks (processed as similarly as possible to sampling filters in the field) should be sampled, digested and determined.

Contamination risk and memory effects are not negligible especially for ubiquitous metals. Usually the metal determination is more limited by the sampling procedure and sampling preparation than by detection limits of the analytical method [18]

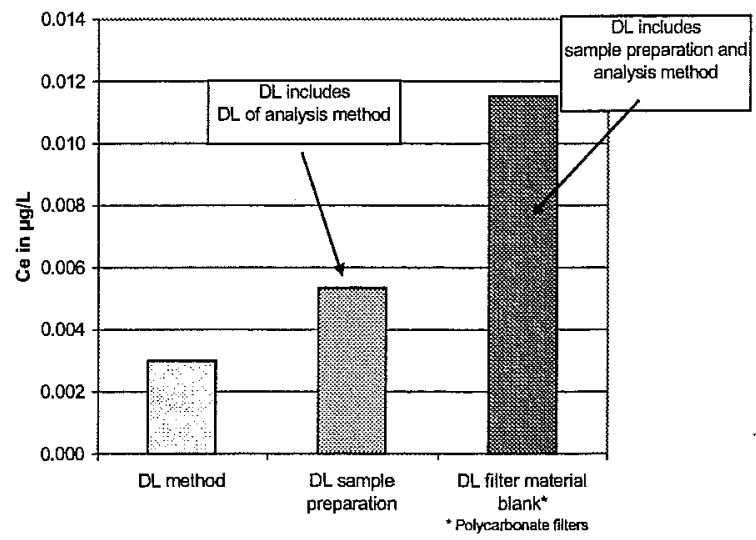

Fig. 7: Detection limits (DL) for different steps : shows how different steps of the entire procedure contribute to the detection limit.

\section{UTILITY ENGINE TESTS WITH CE AND FE ADDITIVES}

\section{Test engine}

Manufacturer: LIEBHERR

Type: $\quad 914 \mathrm{~T}$

Displacement: $\quad 6.11$ liter

Rated power: $\quad 105 \mathrm{~kW}$ at 2'000 RPM

Turbocharger without charge-air cooling

Cycle

ISO 8178/4 C1

8 operating points

Total cycle time: $100 \mathrm{~min}$

Cycle is driven twice

Transition from operating point to operating point is part of the total cycle as typical transient phases.

Fuel

$\begin{array}{ll}\text { Diesel fuel } & \text { as per EN SN } 590 \\ \text { Sulfur content: } & 94 \mathrm{ppm} \\ \text { Poly aromatics: } & 3.5 \mathrm{ppm} \\ \text { Density: } & 0.832 \\ \text { Cetane number: } & 56.6\end{array}$

Lubricant

DEA DES/6069

Sulfur content:

TBN:

$5 \mathrm{ppm}$

$0.55 \mathrm{mg} \mathrm{KOH} / \mathrm{g}$

FBC for trap regeneration

Cerium content: $12 \mathrm{ppm}$

Iron content: $\quad 5 \mathrm{ppm}$

Manufacturer: $\quad$ Rhodia Electronics, France 


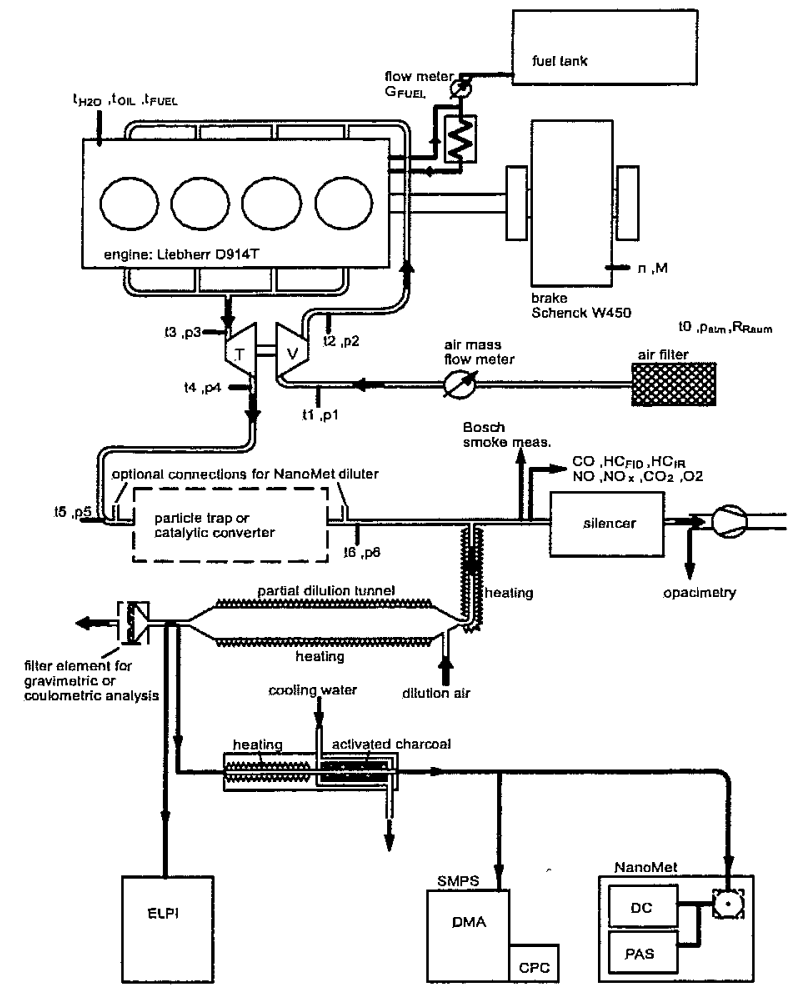

Fig. 8: Test rig schematic for the VERT suitability testing of particle trap systems.

\section{Results}

Figure 9 shows the Cerium and Iron content of the 12 ELPI stages as mass per impactor stage. The base levels of Iron and Cerium were determined using Diesel fuel without additive (designated R020) and without particle trap. Subsequently, additive was mixed with the same Diesel fuel and samples taken without and with particle trap, to analyze for $\mathrm{Ce}$ and $\mathrm{Fe}$.

The following designations are used in the charts:

RO: Reference without additive without trap

CO: Without trap, $10 \mathrm{ppm}$ Chlorine

CF: With trap $10 \mathrm{ppm}$ Chlorine

HCO: Without trap, $100 \mathrm{ppm}$ Chlorine

HCF: With trap, $100 \mathrm{ppm}$ Chlorine

The supplementary Chlorine serves to improve $\mathrm{PCDD} / \mathrm{F}$ verification and increase sensitivity.

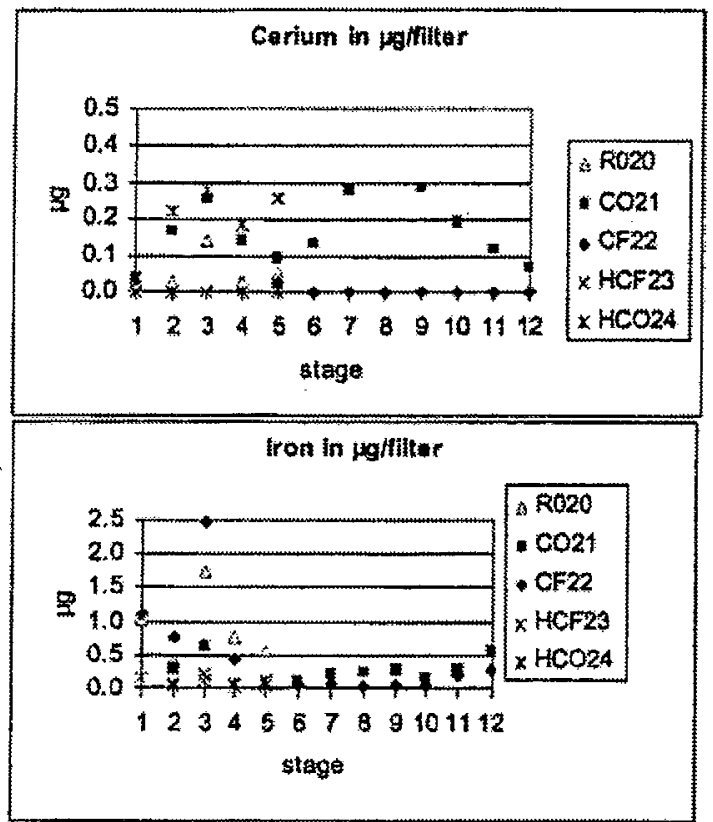

Fig. 9: Size specific metal mass found on the impactor filter in $\mu \mathrm{g} / \mathrm{filter}$

The Cerium content of the no-additive reference fuel sample RO20 is close to the detection limit. Significant quantities of Cerium are detected for the samples $\mathrm{CO} 21$ and $\mathrm{HCO} 24$ from the additive fuel without particle trap. In comparison, the samples CF22 and HCF23, taken from cleaned gas after the particle trap, only contained extremely low Cerium concentrations.

The results are less clear for Iron, a ubiquitous element present in high concentrations throughout the technical system. Under the given test conditions, Iron originating from the additive could not be clearly distinguished from the Iron of other sources (engine, fuel, test facility, sampling unit, ambient air, etc.).

A mass balance was deduced by comparing the measured analyte content with the total mass of additive content. To do this, the metal mass on the ELPI foils are extrapolated for the total emissions, based on the dilution ratio in sampling.

\begin{tabular}{|l|r|}
\cline { 2 - 2 } \multicolumn{1}{c|}{} & \multicolumn{1}{c|}{ Cerium } \\
\hline Additive quantity & $473 \mathrm{mg}$ \\
\hline Total mass ELPI without trap & $2.05 \mu \mathrm{g}$ \\
Total mass ELPI with trap & $0.037 \mu \mathrm{gg}$ \\
\hline Total mass exhaust gas without trap & $15.37 \mathrm{mg}$ \\
Total mass exhaust gas with trap & $0.27 \mathrm{mg}$ \\
\hline Deposition in engine & $457 \mathrm{mg}$ \\
Deposition in trap & $15.1 \mathrm{mg}$ \\
Emitted into ambient & $0.27 \mathrm{mg}$ \\
\hline Filtration rate in engine & $96.7 \%$ \\
Filtration rate in trap & $98.2 \%$ \\
Total filtration rate system & $99.94 \%$ \\
\hline Emissions factor & $0.96 \mu \mathrm{g} / \mathrm{kWh}^{3}$ \\
& $0.2 \mu \mathrm{g} / \mathrm{Nm}^{3}$ \\
\hline
\end{tabular}

Table 1: Mass balance for additive Cerium Total mass per cycle 


\begin{tabular}{|l|r|}
\cline { 2 - 2 } \multicolumn{1}{c|}{} & \multicolumn{1}{c|}{ Iron } \\
\hline Additive quantity & $202 \mathrm{mg}$ \\
\hline Total mass ELPI without trap & $4.32 \mu \mathrm{g}$ \\
Total mass ELPI with trap & $5.76 \mu \mathrm{gg}$ \\
\hline Total mass exhaust gas without trap & $25.6 \mathrm{mg}$ \\
Total mass exhaust gas with trap & $43.2 \mathrm{mg}$ \\
\hline Deposition in engine & $176 \mathrm{mg}$ \\
Deposition in trap & $-17.6 \mathrm{mg}$ \\
Emitted into ambient & $43.2 \mathrm{mg}$ \\
\hline Filtration rate in engine & $87.3 \%$ \\
Filtration rate in trap & $-145 \%$ \\
Total filtration rate System & $78.6 \%$ \\
\hline Emissions factor & $632 \mu \mathrm{g} / \mathrm{kWh}$ \\
& $39 \mu \mathrm{g} / \mathrm{Nm}^{3}$ \\
\hline
\end{tabular}

Table 2: Mass balance for additive Iron Total mass per cycle

These results indicate the very high level of Cerium filtration in the form of Ceroxide particles. It is a very satisfactory result for air pollution control.

An unexpectedly large proportion of the additive substance is retained in the engine. Earlier investigations showed that additive substances are deposited in the engine and the exhaust system. This is referred to as conditioning the engine and may take several hundred hours. During this period, the internal engine additive effect continuously improves. Presumably, after this "conditioning phase", a saturation of the deposition occurs.

After prolonged operations, a substantially higher proportion of the additive might reach the trap. The high deposition level observed could therefore be due to the short test period during the initial deposition phase.

The interpretation of the analysis results for iron is very much more difficult. Whilst it is clear that a substantial quantity of the fuel borne iron is retained within the engine, integration of the results indicates the physical impossibility that the trap has a negative filtration rate! In particular, the run CF22 (i.e.with trap) gave much more iron than did run $\mathrm{CO} 21$ (without trap, otherwise identical), especially on stage 3 . Further, on certain stages, the base run (RO20) gave higher emissions than any additised run, with or without trap. This is consistent with a pattern of deposition of ironcontaining deposits within the system and their later re-entrainment, on a chaotic or random basis.

One possible method to clarify the source is to use an additive having an Iron isotope ratio significantly different from the natural Iron isotope range. Thus the source could be determined with mass spectrometric analysis of the $\mathrm{Fe}$ isotopes. Unfortunately, the necessary materials for preparing such an additive could not be obtained and this investigation was not yet possible.

The data in Table 1 and Table 2 are not corrected for the background values (blanks). The blanks have extremely low Cerium, an order of magnitude below the measured values. For Iron, the blanks have a value of about $30 \%$ of the measured values. Hence, the background levels do not create measurement uncertainty.

The detection limit of the procedure (determined from $3 x$ standard deviation of 5 blank measurements) is in the range of 0.0001 to $0.01 \mu \mathrm{g}$ Cerium per filter. For Iron it is 0.04 to $0.2 \mu \mathrm{g}$ per filter. This is, particularly for Cerium, at a safe level below the measured values.

There is no estimate for the system deposition in the entire experimental setup. It could possibly cause an over-estimation of deposition in the engine and an under-estimation of the filtration rate in the particle trap.

The test cycle spans both accumulation and regeneration phases, i.e. the results of Tables 1 and 2 are an integral of the entire trap response. Hence, it is impossible to distinguish between different operating phases; i.e. the emission quantities cannot be assigned to individual phases.

The re-entrainment artifacts affect the Iron samples. Because Cerium is very seldom in engine systems, the Cerium analysis is substantially more dependable and forms the basis of the conclusions.

The results substantiate that the additive substances are trapped to a very high percentage. This proves that consequent pollution of the environment is very low. Nevertheless, only such metals can be permitted as additive substances, which are known to be not toxic.

Ongoing investigations will verify whether the trap behavior changes during prolonged operations.

\section{CONCLUSIONS}

Metallic additives can be added to the fuel and finely mixed to promote catalytic effects of their oxides during light-off of the deposited soot at low operating temperatures. Additives only escape into the environment in comparatively negligible quantities, when an appropriate particle trap is employed. Comprehensive secondary emission measurements, within the framework of the VERT suitability tests for trap systems, show that for all certified additives more than $99 \%$ of the additives are trapped.

An unexpectedly high proportion of the additive substances is deposited in the engine and exhaust system. Only $10 \%$ reached the particle trap during these tests. This observation can be explained as the initial phase of a deposition phenomenon. Hence, after prolonged operation, substantially more additive substance, if not the entire mass, would reach the trap and be efficiently retained there.

These observations support the concept of the VERT trap suitability tests. VERT stipulates a comprehensive investigation of secondary emissions from all trap regeneration systems having catalytic function (coating and additive). The VERT specifications also stipulate for FBC- systems a supplementary size-specific metal analysis in the after-trap flow, and also verification of the filtration response during accumulation and regeneration phases. This test is mandatory for every 
combination of additive with every trap type, both in new state and after 2000 operating hours.

\section{ACKNOWLEDGEMENT}

The authors would like to thank the participants of the VERT secondary emission programs to provide the data for this paper and Dr.S.Cook / OCTEL for careful review and very valuabie comments to improve the proper description of these phenomena.

\section{REFERENCES}

1. J.Lemaire et al; Regeneration of DPF at low temperatures with the use of a Cerium based fuel additive, SAE 960135

2. A. Mayer, G. Emig et al., Passive Regeneration of Catalyst Coated Knitted Fiber Diesel Particulate Traps, SAE 960138

3. M. Kasper, Ferrocene, Carbon Particles, and PAH in a Methane Diffusion Flame, ETH PhD- Thesis No. $12725 / 1998$

4. M. Kasper et al., Formation of Carbon in Combustion: The Influence of Fuel Additives, Proceedings of the Workshop on Particle Measurement at ETH Zurich, August 7, 1997

5. U. Matter, K. Siegmann; The Influence of Particle Filter and Fuel Additives on Turbo Diesel Engine Exhaust, J. Aerosol Sci., Vol. 28, Suppl. 1, pp.551552,1997

6. Swiss Ordinance on Air Pollution Control Schweizerische Luftreinhalteverordnung LRV 3.Feb.1998, Ziff 14, Anhang 5

7. G. Skillas et al., The Influence of Additives on the Size Distribution and Composition of Particles Produced by Diesel Engines, Combust. Sci. and Tech. 2000, VI. 154, pp 259-273
8. A. Mayer et al., Particulate Traps for Retro-Fitting Construction Site Engines VERT, SAE 1999-010116

9. M.Costantini, Relation between particle metal content (with focus on iron) and biological resonses. ETH-Conference on Nanoparticle Measurement August 2000.

10. Evaluation of human health risk from Cerium added to Diesel fuel. HEI (Health Effect Insitute, Boston) -Communication August 2002

11. Ultrafeine Teilchen und deren Agglomerate BIA (Berufsgenossenschaftliches Institut für Arbeitssicherheit, Sankt Augustin, Germany) Communication, March 1998

12. G.Belot, PSA, Seriegerechte Partikelfilterlösung für PKW's aller Grössenklassen, Seminar Haus der Technik München Juni 2001

13. BUWAL/Suva-Vert-Filterliste - Geprüfte und erprobte Partikelfilter-Systeme für die Nachrüstung von Dieselmotoren, Stand 17.Juli. 2002. (Source: www.umwelt-schweiz.ch/buwal/de/fachgebiete/fgluft/vorschriften/industrie_gewerbe/filter/)

14. Nachrüstung von Fahrzeugen mit Partikelfiltern in der Schweiz, Weisung des Eidgenössischen Justiz- und Polizeidepartementes 7.August 1990.

15. Heeb et al, Secondary Emissions from Catalytic Particle Filter Systems, SAE 2003-01-0291

16. A. Mayer, J. Czerwinski, F. Legerer, M. Wyser, VERT Particulate Trap Verification, SAE 2002-010435

17. J. Keskinen, K. Pietarinen, M. Lehtimaki, Electrical Low Pressure Impactor, J. Aerosol Sci 23/1992, 353-360

18. A. Uirich, A. Wichser, Metal analysis of Diesel vehicle emissions, 6. Conference on NanoparticleMeasurement, Zürich, Aug. 2002. 